\title{
Benefits of a Diversified Energy Mix for Islanded Systems
}

\author{
Marine Cauz ${ }^{1,2 *}$, Lionel Bloch ${ }^{1}$, Christian Rod ${ }^{2}$, Lionel Perret ${ }^{2}$, Christophe Ballif ${ }^{1,3}$ and \\ Nicolas Wyrsch ${ }^{1}$
}

${ }^{1}$ École Polytechnique Fédérale de Lausanne (EPFL), Institute of Microengineering (IMT), Photovoltaics and Thin Film Electronics Laboratory (PV-Lab), Neuchâtel, Switzerland, ${ }^{2}$ Planair SA, Yverdon-les-bains, Switzerland, ${ }^{3}$ Centre Suisse d'Electronique et de Microtechnique (CSEM), PV-Center, Neuchâtel, Switzerland

OPEN ACCESS

Edited by:

Davide Astiaso Garcia,

Sapienza University of Rome, Italy

Reviewed by:

Farrukh Khalid,

Hamad bin Khalifa University, Qatar

Onur Taylan,

Middle East Technical University,

Turkey

*Correspondence:

Marine Cauz

marine.cauz@epfl.ch

Specialty section:

This article was submitted to

Sustainable Energy Systems and

Policies,

a section of the journal

Frontiers in Energy Research

Received: 10 April 2020

Accepted: 15 June 2020

Published: 22 July 2020

Citation:

Cauz M, Bloch L, Rod C, Perret L, Ballif C and Wyrsch N (2020) Benefits

of a Diversified Energy Mix for Islanded

Systems. Front. Energy Res. 8:147.

doi: 10.3389/fenrg.2020.00147
Achieving energy self-sufficiency is a major challenge for remote areas, especially islands. Various technologies have recently been developed to exploit renewable resources in such areas in order to reduce dependency on fossil fuels. This work focuses on the situation of Easter Island, a representative example of a remote area, and explores the pros and cons of three fully renewable energy mixes used to meet local requirements. This investigation reveals that, while a classic photovoltaic/battery combination allows demands to be met, the installations need to be oversized, leading to a $73 \%$ loss in the total energy produced. By adding alternative energy production sources such as wind turbines and pyrolysis, as well as alternative storage systems such as hydrogen-based storage, the energy loss is divided by a factor of 5 . This more diverse energy mix enables a reasonable electricity price of $0.18 € / \mathrm{kWh}$, which is comparable to the current local prices. This work reinforces the importance of complementary energy production and storage systems to efficiently meet the energy requirements of islands.

Keywords: renewable energies, islands, energy system design, photovoltaics, wind turbine, pyrolysis, storage

\section{INTRODUCTION}

Today, the energy demand of remote areas is met mainly by oil-powered generators-a dependency with economic and ecological consequences. Indeed, the transportation of resources to such areas comes with higher prices as compared to the mainland, while also inducing energy supply uncertainty (Shirley and Kammen, 2013; Kuang et al., 2016). Furthermore, the use of generators produces local gas emissions, such as carbon dioxide $\left(\mathrm{CO}_{2}\right)$, that contribute to global warming (Quadrelli and Peterson, 2007). For these reasons, and in line with national and international mid-term energy transition plans toward green technologies such as those proposed in COP21 reports (COP 21, 2015), various initiatives aim at fostering the use of renewable energies for islands (Dorotić et al., 2019). For example, the Small Island Developing States (SIDS) Lighthouses Initiative provides a global framework for energy transition on islands (WHO, 2018) and the Smart Islands Initiative was developed by the European Union to encourage innovative islands solutions that support sustainable economic growth (Smart Islands Initiative, 2016).

In this context, several islands have developed energy planning strategies to reduce their dependency on fossil fuels (Garcia and Meisen, 2008; Godina et al., 2015; Kougias et al., 2019; Meza et al., 2019); some have already reached 100\% energy self-sufficiency (Sperling, 2017). Currently, the use of photovoltaic (PV) and wind-based power systems combined with lithium-ion batteries is preferred due to the good availability of resources and the maturity of these technologies (Thomas et al., 2016; Hall and Swingler, 2018). However, this energy mix has also been shown to have some 


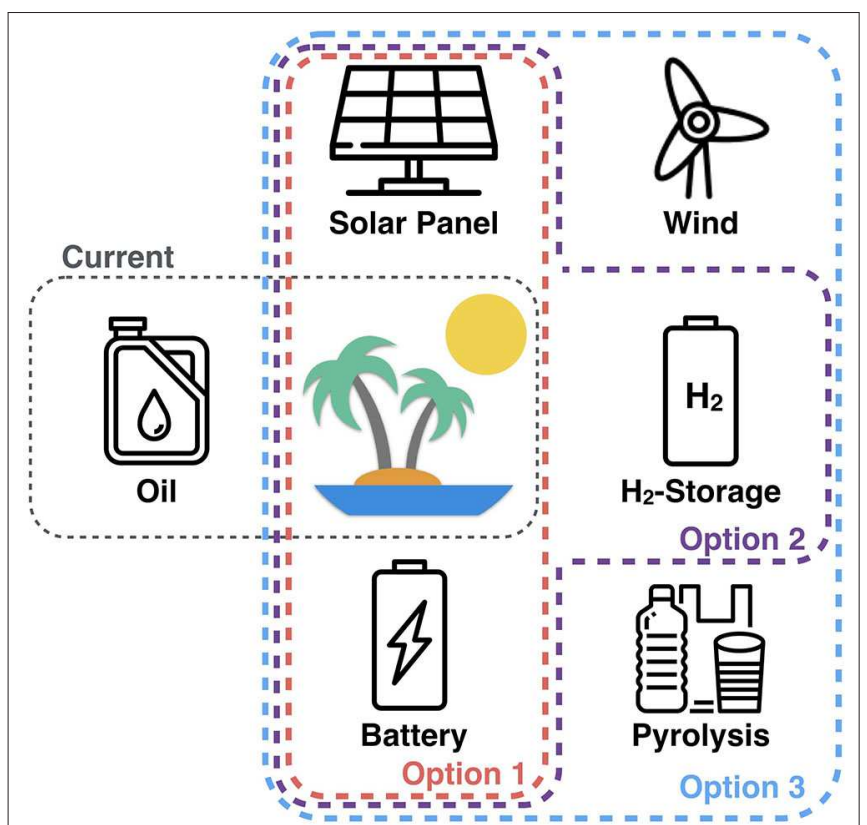

FIGURE 1 | Illustration of the different options explored.

limitations, such as insufficient robustness to extreme weather events and limited long-term storage (Sinsel et al., 2020). Today, various novel technologies that could be used to define more-efficient renewable energy mixes exploiting local resources are being developed. For example, biomass can be used as an alternative production source while also exploiting the availability of organic waste (Selosse et al., 2018). Similarly, pyrolysis technologies have been adapted to efficiently deal with the low waste volumes typically encountered on islands, coupling energy production and waste processing (ETIA, 2019). Regarding storage, a lot of attention has been devoted recently to hydrogenbased storage that, despite having a lower efficiency than lithiumion batteries, is able to absorb production fluctuations on longer time scales (e.g., seasonal) than lithium-ion-based storage allows (Groppi et al., 2018; Abe et al., 2019; Staffell et al., 2019).

Most studies mentioned above illustrate the benefits of a given technology within a specific energy mix. In contrast, this work explores the financial and performance advantages and disadvantages of different energy mixes. These mixes include various novel and classic production and storage units, such as the compact pyrolysis process described above that has, to the best of our knowledge, not been considered within renewable energy planning for islands. Concretely, as illustrated in Figure 1, three fully renewable energy mixes that meet the energy requirements of Easter Island are considered: [Option 1] PV panels with lithium-ion batteries, [Option 2] PV panels with battery-based and hydrogen-based storage, and [Option 3] PV panels, wind turbines, and pyrolysis with battery-based and hydrogen-based storage. After describing the modeling assumptions considered in this study, we present the sizing of the different storage and production systems that minimize investment and maintenance costs in the three options. Then the corresponding performance and economic pros and cons of the different options are discussed and compared to the current situation. Although this study focuses on Easter Island, we believe our approach and main conclusions can be extended to other islands facing similar challenges, such as reaching energy selfsufficiency or reducing plastic pollution.

\section{METHODS}

This work considers three energy mix options that combine three different production sources and two different storage systems (Figure 1). The following production sources were considered: (i) PV panels, as this resource is classically used in islands, especially those benefiting from strong sunshine; (ii) wind turbines, because wind resources are usually favorable on islands; and (iii) pyrolysis. The latter produces energy from the burning of plastic waste, thereby contributing to reduce plastic pollution (Race for Water, 2018). We considered two storage systems: lithium-ion batteries, which have been shown to be efficient in smoothing daily fluctuations of production and consumption, and hydrogen-based storage, which accommodates seasonal fluctuations (Pierre and Luc, 2020).

We consider data from Easter Island, one of the most-remote inhabited islands in the world, located more than $3,500 \mathrm{~km}$ from the nearest continental point. The triangle-shaped island extends over $164 \mathrm{~km}^{2}$, with a local population of 7,700 inhabitants in 2017 (Instituto Nacional de Estadísticas, Chile, 2017). During the tourist season, the population grows significantly with around 100,000 visitors (Casey and Haner, 2018). The climate of Easter Island is maritime subtropical; the temperatures typically vary between 16 and $25^{\circ} \mathrm{C}$ with average wind speeds between 20 and $30 \mathrm{~km} / \mathrm{h}$. The island benefits from an annual horizontal irradiation of $1,544 \mathrm{kWh} / \mathrm{m}^{2}$ (Meteoblue, 2017). Currently, energy is supplied by six diesel-based generators (Centro Energia, 2015), for an overall annual electricity consumption of $13.2 \mathrm{GWh}$, with a minimal permanent power of approximately $1 \mathrm{MW}$ in 2017. In 2018, the first PV generation plant composed of 400 solar panels providing a total power of $100 \mathrm{kWp}$ was inaugurated (Chile's Ministry of Energy, 2018).

\section{Modeling and Optimization Framework}

The optimization framework takes as its input local constraints (weather, waste and consumption) and the technical features of technologies considered. Concretely, the 2017 energy consumption curve was obtained from the Easter Island's distributed system operator. Then, based on the weather and waste data of the same year, a unit hourly annual curve was computed for all power supply units (PV, wind, pyrolysis). Finally, for each option, a continuous mixed-integer linear programming (MILP) optimization algorithm was used to identify the optimal combination of different sources and storage systems to meet the 2017 energy requirements of the island at the lowest cost. The MILP approach was chosen because it is one of the state-of-the-art methods in such applications (Alberizzi et al., 2020), it is well-documented with several commercial solvers, and thanks to the convexity of linear problems the solution is guaranteed to be globally optimal (Urbanucci, 2018). 
The main constraint of the optimization problem consists in balancing energy production and uses at each time point, which can be expressed as follows:

$$
\sum_{i} P_{i, t}^{\text {produced }}+\sum_{i} P_{i, t}^{\text {discharged }}=P_{t}^{\text {load }}+\sum_{i} P_{i, t}^{\text {charged }}+\sum_{i} P_{i, t}^{\text {lost }}
$$

where $i$ reflects the (storage or production) system being considered, $P_{i}^{\text {produced }}$ is the power production, $P_{i}^{\text {discharged }}$ is the discharge power, $P^{\text {load }}$ is the power consumed, $P_{i}^{\text {charged }}$ is the power stored, and $P_{i}^{\text {lost }}$ corresponds to power losses (i.e., curtailment and efficiency losses). These measurements are evaluated at each time index $t$, encoding an hourly sampling over the year considered. The relationship described in Equation (1), as well as the constraints described here after, is verified for any $t$ within this range.

The following modeling assumptions and forecast production curves were considered:

- PV - We used the PVSyst software (PVsyst SA, 2020) to simulate an hourly production curve for $1 \mathrm{kWp}$ from the 2017 weather data of Easter Island (Meteoblue, 2017). This normalized curve was generated considering a tilt of $10^{\circ}$ and the four possible cardinal orientations. To compute the global annual cost, we considered the lifetime of PV systems to be 25 years, and the associated costs were obtained from SwissSolar (Swisssolar association, 2020). The main constraint applied to the PV system is:

$$
P_{\mathrm{PV}, t}^{\text {produced }}=P_{\mathrm{PV}}^{\text {nominal }} \cdot P_{\mathrm{PV}, t}^{\text {normalized }}
$$

where $P_{\mathrm{PV}, t}^{\text {produced }}$ is the power production of the PV system, $P_{\mathrm{PV}}^{\text {nominal }}$ is the nominal power of the $\mathrm{PV}$ system, and $P_{\mathrm{PV}, t}^{\text {normalized }}$ is the normalized produced power given by the simulated production curve.

- Wind turbine - We used the power distribution curve of the Enercon E-82 (2350 kW) wind turbine (SuisseEole, 2020b). This curve was then multiplied with the 2017 hourly wind speed to obtain a unitary wind turbine production curve. We considered this wind turbine model because its height (78 $\mathrm{m}$ ) approximately matches the height of the wind speed data available. The lifetime of wind turbines was assumed to be 25 years with associated costs from SuisseEole (2020b). As for the PV system, wind production is also submitted to the following constraint:

$$
P_{\mathrm{W}, t}^{\text {produced }}=P_{\mathrm{W}}^{\text {nominal }} \cdot P_{\mathrm{W}, t}^{\text {normalized }}
$$

where $P_{\mathrm{W}, t}^{\text {produced }}$ is the power produced by the wind turbine at time $t, P_{\mathrm{W}}^{\text {nominal }}$ is its nominal power, and $P_{\mathrm{W}, t}^{\text {normalized }}$ is the normalized produced power at time $t$ given by the production curve described above.

- Pyrolysis - The amount of pyrolysis-based production was determined by the plastic waste production of the island. We considered the Biogreen 300 reference installation (Race for Water, 2018), processing $200 \mathrm{~kg} / \mathrm{h}$ of plastic waste with a higher calorific value greater ( $\mathrm{HCV}$ ) than $34.2 \mathrm{MJ} / \mathrm{kg}$, resulting in an annual energy production of $353 \mathrm{~kW}$ multiplied by 7,500 $\mathrm{h}$ per year. The installation was assumed to be turned off for maintenance for the first $105 \mathrm{~h}$ of each month, and to then produce a constant power. The lifetime of the pyrolysis system has been estimated at 15 years, and the associated costs were provided by ETIA (ETIA, 2019).

- Lithium-ion battery storage - The charging and discharging efficiency of these batteries was assumed to be 90\% (Pierre and Luc, 2020). A lifetime of 10 years was considered, and associated costs were obtained from NREL (Cole and Frazier, 2019). The constraints associated with this storage system are the following:

$$
\begin{aligned}
P_{t}^{\text {charged }} & \leq R^{\text {charge max }} \cdot E^{\text {max }} \\
P_{t}^{\text {charged }} & \leq \sum_{i=1}^{N} P_{i, t}^{\text {produced }}-P_{t}^{\text {load }} \\
E_{t+1}^{\text {stored }} & =E_{t}^{\text {stored }}+E_{t}^{\text {charged }} \cdot \eta_{\mathrm{c}}-E_{t}^{\text {discharged }} \cdot \frac{1}{\eta_{\mathrm{d}}} \\
P_{t}^{\text {discharged }} & \leq R^{\text {discharge max }} \cdot E^{\text {max }} \\
P_{t}^{\text {discharged }} & \leq P_{t}^{\text {load }}-\sum_{i=1}^{N} P_{i, t}^{\text {produced }} \\
E_{t}^{\text {stored }} & \leq E^{\text {max }} \\
E_{t_{\text {initial }}^{\text {stored }}} & \leq E_{t_{\text {end }}}^{\text {stored }}
\end{aligned}
$$

where $P_{t}^{\text {charged }}$ (resp. $P_{t}^{\text {discharged }}$ ) represents the power charged (resp. discharged) in the storage system at time $t, E_{t}^{\text {charged }}$ (resp. $E_{t}^{\text {discharged }}$ ) represents the energy charged (resp. discharged) in the storage system at time $t, R^{\text {charge max }}$ (resp. $R^{\text {discharge max }}$ ) is the maximum charging (resp. discharging) rate, $\eta_{\mathrm{c}}$ (resp. $\eta_{\mathrm{d}}$ ) is the charging (resp. discharging) efficiency and $E^{\max }$ is the total capacity of the storage system. Equation (9) ensures that the stored energy at any time $t$ is always lower than the total capacity of the storage system and Equation (10) implies that the amount of energy stored in the system at the end of the year $\left(E_{t_{\text {end }}}^{\text {stored }}\right)$ is greater than or equal to the energy available initially $\left(E_{t_{\text {initial }}}^{\text {stored }}\right)$.

- Hydrogen-based storage - The efficiency of the electrolyser to transform electricity into hydrogen was fixed at $60 \%$, and the efficiency of the fuel cell to convert hydrogen back into electricity was set at 50\%, resulting in an overall battery efficiency of 30\% (Pierre and Luc, 2020). The elements of hydrogen-based storage were assumed to have a lifetime of 20 years with associated costs from ADEME (2019). The constraints associated with this storage system are the same as those described in Equations (4)-(10) for lithium-ion batteries with adapted parameter values.

These constraints, together with the corresponding OPEX and CAPEX costs, were gathered into the MILP problem, which was solved using Gurobi software 
(Gurobi, 2020). More precisely, we solved the following optimization problem:

$$
\min _{\alpha \in \mathcal{P}} \sum_{i=1}^{N} G_{i}(\alpha)
$$

where $\alpha$ is the set of parameters to be determined (e.g., battery sizes, etc.) submitted to the set of constraints encoded in $\mathcal{P}, i$ reflects the (storage or production) system being considered, $N$ is the total number of such systems and is different in the three options, and $G_{i}(\alpha)$ is the global annual cost associated with the system $i$. This cost is given by $G_{i}(\alpha)=C_{i}(\alpha) / L_{i}+O_{i}(\alpha)$, where $C_{i}(\alpha)$ (resp. $\left.O_{i}(\alpha)\right)$ is the CAPEX (resp. OPEX) of the system $i$ being considered, and $L_{i}$ is the corresponding lifetime.

\section{RESULTS}

To better describe the three proposed options, we now detail the optimal solution found in each case based on the energy planning involved, the corresponding energy flow structure and the associated investment and electricity costs.

\section{Energy Planning}

Table 1 presents the nominal capacities of energy sources and storage systems required in each option.

TABLE 1 | CAPEX, OPEX, lifetime, and optimal nominal capacities of the energy sources and storage systems (for MW-scale systems) in the three options.

\begin{tabular}{|c|c|c|c|c|c|c|c|c|}
\hline & & \multirow{2}{*}{$\frac{\text { CAPEX }}{[k €]}$} & \multirow{2}{*}{$\frac{\text { OPEX }}{[k €]}$} & \multirow{2}{*}{$\frac{\text { Lifetime }}{\text { [year] }}$} & \multicolumn{3}{|c|}{ Option } & \\
\hline & & & & & 1 & 2 & 3 & \\
\hline \multirow[t]{3}{*}{ Source } & PV & $74+884 \cdot \beta$ & $11 \cdot \beta$ & 25 & 36.65 & 22.58 & 7.86 & [MWp] \\
\hline & Pyrolysis & 2,500 & 150 & 15 & - & - & 0.35 & {$[\mathrm{MW}]$} \\
\hline & Wind turbine & $1,425 \cdot \beta$ & $49 \cdot \beta$ & 25 & - & - & 2.57 & {$[\mathrm{MW}]$} \\
\hline \multirow[t]{4}{*}{ Storage } & Lithium-ion & $310 \cdot \beta$ & $8 \cdot \beta$ & 10 & 42.52 & 25.78 & 17.52 & [MWh] \\
\hline & Hydrogen & $18 \cdot \beta$ & $0.18 \cdot \beta$ & 20 & - & 85.21 & 106.96 & [MWh] \\
\hline & Electrolyser & $1,200 \cdot \beta$ & $60 \cdot \beta$ & 20 & - & 1.20 & 0.553 & {$[\mathrm{MW}]$} \\
\hline & Fuel cell & $3,000 \cdot \beta$ & $150 \cdot \beta$ & 20 & - & 0.65 & 0.65 & {$[\mathrm{MW}]$} \\
\hline
\end{tabular}

Costs are given by a linear function of the amount of nominal power or capacity installed, denoted $\beta$, with units shown in the last column. For example, the CAPEX for the lithiumion battery in Option 2 is $310 \cdot 25.78=7992 \mathrm{k} €$. The sources for CAPEX, OPEX, and lifetime values are reported in subsection Modeling and optimization framework.
Several observations can be made from these results. First, regarding the energy production resources, it can be seen that in Option 1 the PV resource is oversized because it is the only energy production resource. This oversizing is also observed in Option 2 even though the diversification of the storage systems somewhat mitigates this effect. In contrast, in Option 3, the use of a diversified energy resource mix results in a large decrease in the PV nominal capacity as compared to Options $1(78 \%$ decrease) and 2 (65\% decrease). Comparing storage allocations in Options 1 and 2, we observe that the overall storage capacity is increased by $161 \%$ in Option 2 by including hydrogen-based storage, thereby decreasing the need for energy production. Note that the optimal scenario in Option 3 involves an intensive use of hydrogen-based storage, which suggests that this type of storage is crucial to integrate the diversity of energy resources.

\section{Flow Structure}

We now examine the annual optimal energy flow structure obtained in the three options. Figure 2 is a Sankey diagram illustrating these flows between energy sources, storage systems and uses. More precisely, the flows represent the amount of annual energy transiting from a source either to a specific storage system or to a direct use (consumption or loss). The energy part directly going from a source to losses corresponds to the amount of curtailed electricity. From a storage system, the energy is divided between the part which can be consumed and the losses that reflect the efficiency of the storage systems. Note that the curve widths are proportional to the energy flows within each option, but are not directly comparable between options as consumption $(\mathbf{C})$ remains constant in each case.

In Option $1,73 \%$ of the production is lost and only $12 \%$ is directly used. The battery-based storage stores $19 \%$ of the annual PV production and returns that energy with $90 \%$ efficiency. Overall, this option is found to induce the highest energy losses (73\%) among the three options. By including hydrogen-based storage, Option 2 decreases the proportion of energy lost (56\%) by storing an additional part of the PV production. Note, however, that hydrogen-based storage is $70 \%$ less efficient than lithium-ion batteries. Option 3 presents the lowest energy loss (33\%) coming mainly from the limited efficiency of hydrogenbased storage. Almost all the energy produced by pyrolysis and wind turbines is directly consumed, thereby making the proportion of battery-based consumed energy lower than in Options 1 and 2. Finally, note that since consumption (C) is
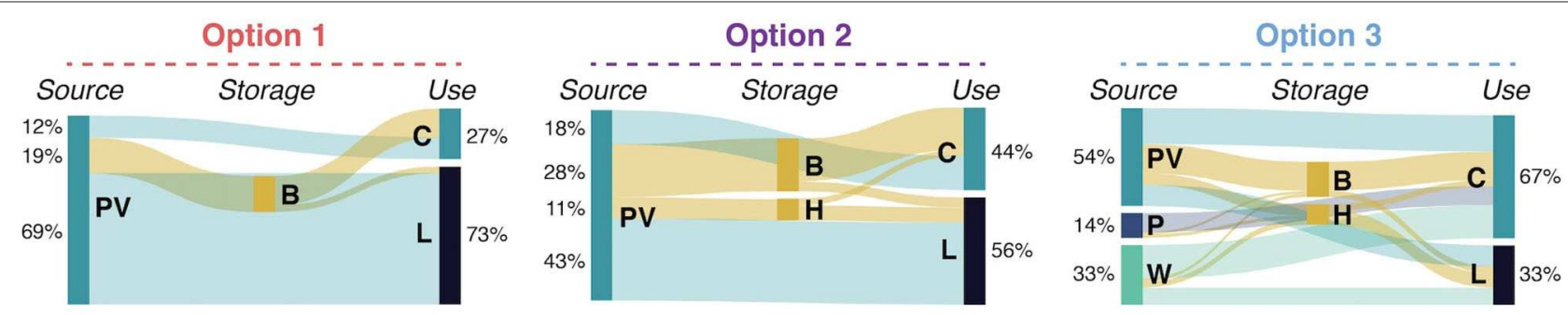

FIGURE 2 | Summary of the annual energy fluxes between energy sources, storage systems and uses. Energy sources include photovoltaic (PV), wind turbines (W) and pyrolysis (P); storage systems include lithium-ion batteries (B) and hydrogen-based storage (H); and uses include consumption (C) and losses (L). 


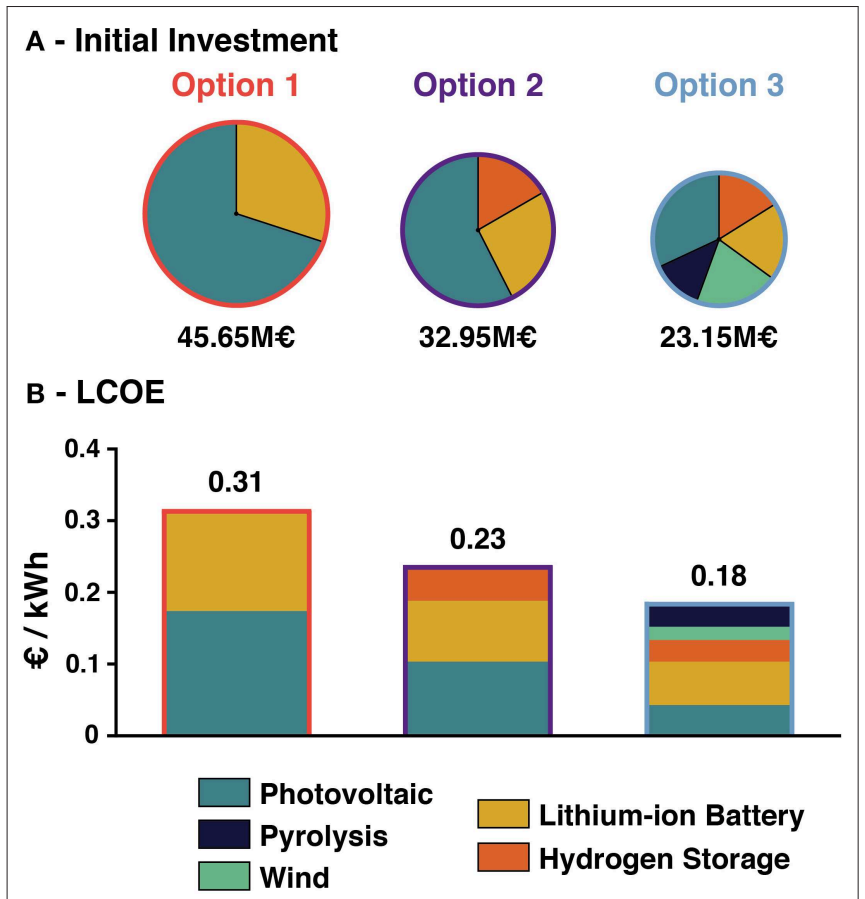

FIGURE 3 | (A) Initial investment costs for each option in millions of $€$ and (B) the levelized cost of energy (LCOE) based on the energy consumed over the first year. A discount rate of $3 \%$ was considered to compute the LCOE.

constant across all options, the amount of losses is proportionally more important in Option 1 than in Options 2 and 3 because the total energy production is higher in Option 1. For example, the ratio between the amount of losses in Options 1 and 3 is equal to $(73 \% / 33 \%) \cdot(67 \% / 27 \%)=5.49$, which is bigger than expected by merely comparing the percentage of losses in these two cases.

\section{Cost Study}

The options presented above should also be discussed from an economic point of view. Figure 3 presents two such aspects of these energy strategies: the investment costs to make the corresponding production and storage systems available (Figure 3A) and the electricity cost during the first year of use (Figure 3B).

It can first be observed from Figure $\mathbf{3 A}$ that the initial investment decreases for options that include a more diversified mix of energy sources and storage systems. A similar observation is made from Figure 3B regarding the electricity cost that includes both the investment and maintenance costs. Moreover, it can be seen that in Option 3 the costs are distributed across the various energy production and storage systems. In contrast, in Options 1 and 2, the majority of the costs are incurred by the PV resource, which needs to be oversized to meet the consumption constraints, as observed in Figure 2.

\section{DISCUSSION}

We have explored the benefits of a diversified energy mix using data from Easter Island. We believe the main outcomes of this study can help with thinking about green and autonomous energy transitions for islands and other remote areas.

\section{On the Importance of a Diversified Energy Mix}

A first conclusion to be drawn from our analysis is that relying on a PV plant as a unique energy production source requires the whole system to be oversized with a significant impact on the installation cost. Indeed, when PV is coupled with lithium-ion batteries, $73 \%$ of energy production is lost (Figure 2, Option 1) because it is more expensive to increase battery capacity rather than decreasing PV power. This result is in line with the conclusions of Katsaprakakis and Dakanali (2019), which compares storage technologies for small insular grids and concludes that a 100\% annual renewable energy sources (RES) penetration cannot be achieved with only an electrochemical storage system. We also observe that coupling lithium-ion batteries with hydrogen-based storage (Option 2) allows for reducing the overall installation cost and energy losses, in agreement with previous observations (Simon and Gils, 2017; Groppi et al., 2018). Including hydrogen-based storage allows for absorbing seasonal PV production fluctuations (Pierre and Luc, 2020) that cannot be captured by lithium-ion batteries, but its limited overall efficiency (30\%) and high cost still cause an energy loss of $56 \%$ when only PV is used as the energy source (Duić et al., 2003). In contrast, including other energy resources as presented in Option 3 decreases both installation costs and energy losses. Indeed, that option exploits the complementary nature of production sources: pyrolysis ensures a baseline production at all times, and PV and wind sources present complementary production profiles (SuisseEole, 2020a). Note that energy losses significantly decrease between Options 2 and 3 because the diversification of energy sources in Option 3 leads to smoother production profiles over the day. This results in a decreased requirement of the electrolyser's nominal power, thereby reducing the associated cost of this expensive storage element (Table 1).

Overall, we find that diversification of both the production and storage systems is essential to meet the energy consumption needs of the island with renewable energies at the lowest cost. The use of hydrogen-based storage is instrumental in this context and, considering recent attention devoted to this technology (Abe et al., 2019; ADEME, 2019; Hirscher et al., 2020), it seems reasonable to expect its cost and efficiency to evolve in the shortto mid-term. On the production side, the complementarity of $\mathrm{PV}$ and wind resources supports recent findings highlighting the potential of combining these resources to improve the robustness of the energy mix (SuisseEole, 2020a). In addition, these two resources are already widely used on various islands (Giatrakos et al., 2009; Hall and Swingler, 2018; Dorotić et al., 2019). We also considered a pyrolysis technology which is still in development. Our results highlight the potential of this technology when 
combined with classical resources, while also assisting with waste management issues that are common to many islands (Lavers et al., 2019; Race for Water, 2020). Other promising renewable energy sources, such as the innovative sea-wave-based technology proposed by (Curto et al., 2019), could be considered to further diversify the energy mix.

\section{Comparison With the Current Situation}

Electricity production on Easter Island is currently supplied by diesel-powered generators, most of which are located near the airport, at the southwest end of the island (Centro Energia, 2015). The exact energy production cost is hard to evaluate as the Chilean government is subsidizing this sector (HACIENDA, 1986). Some sources suggest that the cost is around $0.70 € / \mathrm{kWh}$ while the retail price offered by the Easter Island distribution system operator ranges between 0.08 and $0.32 € / \mathrm{kWh}$ depending on the monthly consumption (SASIPA SpA, 2020). We contend that our calculated cost of $0.18 € / \mathrm{kWh}$ (Figure 3B) for Option 3 is competitive with the current electricity market situation, even if certain limitations of our approach need to be taken into account, as detailed below. Then, it is important to note that moving to a distributed energy production system requires to production sites to be distributed across the island, which is likely to come with additional grid costs and constraints coming from the limited unprotected sites available. Likewise, the impact of wind turbines on the scenery has raised controversy on the island, and it is unclear whether this energy resource will be considered in the near future. One alternative resource to exploit wind with a lower impact on scenery could be the use of kite power, which has shown promising results on boats (Skysail power, 2020).

\section{Limitations and Future Work}

Our results rely on models and assumptions that come with several limitations. First, the whole electrical network and associated maintenance and adaptation costs were not considered. This was motivated by the modeling complexity required to account for these elements, and by the fact that these costs could be considered to be approximately similar across options. Second, we ran our optimization framework on one ideal working year, without accounting for facilities' aging, which might cause, e.g., decreases in their efficiency. Third, the optimization framework is based on economic criteria and using current investment and maintenance costs that might significantly change in the coming years. However, we expect these changes to mildly affect our conclusions, as most of these costs tend to decrease. In addition, the costs of the systems considered are those estimated for Europe and may vary on islands. Fourth, we assumed the annual consumption to remain constant over the years, whereas an annual increase of around $7 \%$ is expected in the coming years on Easter Island (Centro Energia, 2015). Finally, the optimal energy mix is given in terms of nominal power for supply and storage capacities which do not directly provide the optimal number of corresponding units. For example, we find that the optimal nominal wind power in Option 3 is $2.57 \mathrm{MW}$ which does not correspond to an integer number of wind turbines.
Other development lines could be considered to improve the proposed tool and analysis. For example, using 2017 weather recordings allowed us to precisely predict the production of supply units for that year but does not account for climate uncertainties. Note that we used data covering a whole year in order to optimize energy mixes across different seasonal weather patterns, but future work might explore the robustness of different energy mixes to weather condition uncertainties. Finally, alternative energy storage or production sources could be considered such as biomass, tidal power, or mobile storage using electric vehicles depending on the resources available in the areas under study.

\section{CONCLUSION}

In this paper, the impact of diversifying the renewable energy mix of an island is explored. Using weather data and the energy requirements of Easter Island, three 100\% renewable energy mixes are considered: [Option 1] PV panels with lithiumion batteries, [Option 2] PV panels with battery-based and hydrogen-based storage and [Option 3] PV panels, wind turbines, and pyrolysis with battery-based and hydrogen-based storage. For each option, a mixed-integer linear programming (MILP) procedure is used to identify the capacities of supply and storage units providing the lowest investment plus maintenance cost, while meeting the energy needs of the island at any time. The results show that options with more diversified production and storage resources come with both decreased overall cost and energy losses. More precisely, the initial investment and levelized cost of energy (LCOE) of Option 3 are both reduced by around $50 \%$ as compared to the classic PV/battery system (Option 1). In addition, energy losses are reduced by a ratio of 5.49 between Options 1 and 3. The contribution of this research lies in both the quantification of costs associated with different energy mix options and the use of new technologies such as alternative storage systems or the containerized turnkey pyrolysis process. For example, hydrogen-based storage takes advantage of seasonal production fluctuations (e.g., higher PV production during the summer) that cannot be exploited by lithium-ion batteries. Then, the use of pyrolysis improves the robustness of the energy supply while also solving other challenges of islands such as waste management. Overall, this study illustrates the benefits of using diversified energy sources and storage systems to reach a sustainable and renewable energy mix on islands. Future work will aim to improve the modeling of supply and storage units to better integrate their peculiarities (e.g., type of electrolyser, battery state of charge, etc.). The optimization framework could also be extended to design energy planning over more than 1 year, thereby better accounting for system aging and cost fluctuations.

\section{DATA AVAILABILITY STATEMENT}

The raw data supporting the conclusions of this article will be made available by the authors. 


\section{AUTHOR CONTRIBUTIONS}

MC, LB, CR, LP, CB, and NW designed the research. $\mathrm{MC}$ and $\mathrm{CR}$ contributed to the analysis tools. MC, LB, $\mathrm{CR}$, and NW analyzed the data. MC, LB, and NW wrote the paper.

\section{REFERENCES}

Abe, J. O., Popoola, A. P. I., Ajenifuja, E., and Popoola, O. M. (2019). Hydrogen energy, economy and storage: review and recommendation. Int. J. Hydrogen Energy 44, 15072-15086. doi: 10.1016/j.ijhydene.2019.04.068

ADEME (2019). Vers l'autonomie Énergétique des ZNI (Zones non Interconnectées). Technical Report Brochure réf. 010769, ADEME.

Alberizzi, J. C., Rossi, M., and Renzi, M. (2020). A MILP algorithm for the optimal sizing of an off-grid hybrid renewable energy system in South Tyrol. Energy Rep. 6, 21-26. doi: 10.1016/j.egyr.2019.08.012

Casey, N., and Haner, J. (2018). Easter Island Is Eroding. New York, NY: The New York Times.

Centro Energia (2015). Elaboración de Propuesta Energética Para Isla de Pascua.

Chile's Ministry of Energy (2018). BNamericas - Chile Inaugurates the First Photovoltaic Generation Plant in Easter Island. Available online at: https:// www.bnamericas.com/en/news/chile-inaugurates-the-first-photovoltaicgeneration-plant-in-easter-island

Cole, W., and Frazier, A. W. (2019). Cost Projections for Utility-Scale Battery Storage. Technical Report NREL/TP-6A20-73222, National Renewable Energy Laboratory. doi: 10.2172/1529218

COP 21 (2015). COP 21 - Reports | UNFCCC. Available online at: https://unfccc. $\mathrm{int} /$ process-and-meetings/conferences/past-conferences/paris-climatechange-conference-november-2015/cop-21/cop-21-reports

Curto, D., Franzitta, V., Viola, A., Cirrincione, M., Mohammadi, A., and Kumar, A. (2019). A renewable energy mix to supply small islands. A comparative study applied to Balearic Islands and Fiji. J. Clean. Product. 241:118356. doi: 10.1016/j.jclepro.2019.118356

Dorotić, H., Doračić, B., Dobravec, V., Pukšec, T., Krajačić, G., and Duić, N. (2019). Integration of transport and energy sectors in island communities with 100\% intermittent renewable energy sources. Renew. Sustain. Energy Rev. 99, 109-124. doi: 10.1016/j.rser.2018.09.033

Duić, N., Lerer, M., and Carvalho, M. G. (2003). Increasing the supply of renewable energy sources in island energy systems. Int. J. Sustain. Energy 23, 177-186. doi: 10.1080/01425910412331290760

ETIA (2019). Industrial Equipment for Pyrolysis of Plastic.

Garcia, A., and Meisen, P. (2008). Renewable Energy Potential of Small Island States. San Diego, CA. Available online at: http://www.geni.org/globalenergy/ library/technical-articles/generation/small-island-nations/renewable-energypotential-of-small-island-states/Renewable\%20Energy\%20Potential\%20of \%20Small\%20Island\%20States1.pdf

Giatrakos, G. P., Tsoutsos, T. D., Mouchtaropoulos, P. G., Naxakis, G. D., and Stavrakakis, G. (2009). Sustainable energy planning based on a stand-alone hybrid renewableenergy/hydrogen power system: application in Karpathos island, Greece. Renew. Energy 34, 2562-2570. doi: 10.1016/j.renene.2009.05.019

Godina, R., Rodrigues, E., Matias, J., and Catalão, P. S. J. (2015). Sustainable Energy System of El Hierro Island. Available online at: https://www.researchgate.net/ publication/282575056_Sustainable_energy_system_of_El_Hierro_Island

Groppi, D., Astiaso Garcia, D., Lo Basso, G., Cumo, F., and De Santoli, L. (2018). Analysing economic and environmental sustainability related to the use of battery and hydrogen energy storages for increasing the energy independence of small islands. Energy Convers. Manage. 177, 64-76. doi: 10.1016/j.enconman.2018.09.063

Gurobi (2020). Gurobi - The Fastest Solver.

HACIENDA, M. D. (1986). Establece Impuestos a Combustibles Que señala. Ministerio de Hacienda. Available online at: https://www.leychile.cl/Navegar? idNorma $=29903$

\section{ACKNOWLEDGMENTS}

The authors would like to thank the Foundation PlanetSolar for sharing Easter Island data. Icons in Figure 1 are from falticon.com (authors: Freepik, monkik, prettycons, surang and Vectors Market).

Hall, M., and Swingler, A. (2018). Initial perspective on a 100\% renewable electricity supply for Prince Edward Island. Int. J. Environ. Stud. 75, 135-153. doi: 10.1080/00207233.2017.1395246

Hirscher, M., Yartys, V. A., Baricco, M., Bellosta von Colbe, J., Blanchard, D., Bowman, R. C., et al. (2020). Materials for hydrogen-based energy storagepast, recent progress and future outlook. J. Alloys Compounds 827:153548. doi: $10.1016 /$ j.jallcom.2019.153548

Instituto Nacional de Estadísticas, Chile (2017). Proyecciones de Población. Available online at: http://www.ine.cl/estadisticas/sociales/demografia-yvitales/proyecciones-de-poblacion

Katsaprakakis, D., and Dakanali, I. (2019). Comparing electricity storage technologies for small insular grids. Energy Proc. 159, 84-89. doi: 10.1016/j.egypro.2018.12.023

Kougias, I., Szabó, S., Nikitas, A., and Theodossiou, N. (2019). Sustainable energy modelling of non-interconnected Mediterranean islands. Renew. Energy 133, 930-940. doi: 10.1016/j.renene.2018.10.090

Kuang, Y., Zhang, Y., Zhou, B., Li, C., Cao, Y., Li, L., et al. (2016). A review of renewable energy utilization in islands. Renew. Sustain. Energy Rev. 59, 504-513. doi: 10.1016/j.rser.2016.01.014

Lavers, J. L., Dicks, L., Dicks, M. R., and Finger, A. (2019). Significant plastic accumulation on the Cocos (Keeling) Islands, Australia. Sci. Rep. 9, 1-9. doi: 10.1038/s41598-019-43375-4

Meteoblue (2017). Historic Weather Easter Island Data. Available online at: https:// www.meteoblue.com/fr/meteo/archive/export/\%c3\%8ele-de-p\%c3\%a2ques_ chili_4030726

Meza, C. G., Zuluaga Rodríguez, C., D’Aquino, C. A., Amado, N. B., Rodrigues, A., and Sauer, I. L. (2019). Toward a 100\% renewable island: a case study of Ometepe's energy mix. Renew. Energy 132, 628-648. doi: 10.1016/j.renene.2018.07.124

Pierre, S., and Luc, B. (2020). Rendement de la Chaîne Hydrogène. Paris: Fiche technique ADEME, 16.

PVsyst SA (2020). PVsyst Software. Available online at: https://www.pvsyst.com/fr/ fonctionnalite/

Quadrelli, R., and Peterson, S. (2007). The energy-climate challenge: recent trends in CO2 emissions from fuel combustion. Energy Policy 35, 5938-5952. doi: 10.1016/j.enpol.2007.07.001

Race for Water (2018). Biogreen by ETIA|Transformer les Déchets Plastiques en Électricité-Race For Water. Available online at: https://www.raceforwater.org/ $\mathrm{fr} /$ fondation/act/biogreen/

Race for Water (2020). Une Fondation Pour Préserver l'eau. Available online at: https://www.raceforwater.org/fr/

SASIPA SpA (2020). Electricity Prices - SASIPA SpA.

Selosse, S., Garabedian, S., Ricci, O., and Maïzi, N. (2018). The renewable energy revolution of reunion island. Renew. Sustain. Energy Rev. 89, 99-105. doi: 10.1016/j.rser.2018.03.013

Shirley, R., and Kammen, D. (2013). Renewable energy sector development in the Caribbean: current trends and lessons from history. Energy Policy 57, 244-252. doi: 10.1016/j.enpol.2013.01.049

Simon, S., and Gils, H. (2017). Carbon neutral archipelago - 100\% renewable energy supply for the Canary Islands. Appl. Energy 188, 342-355. doi: 10.1016/j.apenergy.2016.12.023

Sinsel, S. R., Riemke, R. L., and Hoffmann, V. H. (2020). Challenges and solution technologies for the integration of variable renewable energy sources-A review. Renew. Energy 145, 2271-2285. doi: 10.1016/j.renene.2019.06.147

Skysail Power (2020). Kitepoer Technology. Available online at: https://skysailspower.com/technology.html 
Smart Islands Initiative (2016). Smart Islands Initiative - About. Available online at: http://www.smartislandsinitiative.eu/en/about.php

Sperling, K. (2017). How does a pioneer community energy project succeed in practice? The case of the Samsø Renewable Energy Island. Renew. Sustain. Energy Rev. 71, 884-897. doi: 10.1016/j.rser.2016.12.116

Staffell, I., Scamman, D., Abad, A. V., Balcombe, P., E. Dodds, P., Ekins, P., et al. (2019). The role of hydrogen and fuel cells in the global energy system. Energy Environ. Sci. 12, 463-491. doi: 10.1039/C8EE01157E

SuisseEole (2020a). Masterplan Éolien suisse : Analyse et Actualisation du Potentiel de L'énergie Éolien en Suisse.

SuisseEole (2020b). Windenergie-Daten der Schweiz. Available online at: https:// wind-data.ch/tools/powercalc.php

Swisssolar association (2020). Swissolar. Available online at: https://www.swissolar. $\mathrm{ch} / \mathrm{fr} /$

Thomas, D., Deblecker, O., and Ioakimidis, C. S. (2016). Optimal design and techno-economic analysis of an autonomous small isolated microgrid aiming at high RES penetration. Energy 116, 364-379. doi: 10.1016/j.energy.2016.09.119
Urbanucci, L. (2018). Limits and potentials of Mixed Integer Linear Programming methods for optimization of polygeneration energy systems. Energy Proc. 148, 1199-1205. doi: 10.1016/j.egypro.2018.08.021

WHO (2018). Air Pollution and Child Health: Prescribing Clean Air. Available online at: http://www.who.int/ceh/publications/air-pollution-child-health/en/

Conflict of Interest: The authors declare that the research was conducted in the absence of any commercial or financial relationships that could be construed as a potential conflict of interest.

Copyright (C) 2020 Cauz, Bloch, Rod, Perret, Ballif and Wyrsch. This is an open-access article distributed under the terms of the Creative Commons Attribution License (CC BY). The use, distribution or reproduction in other forums is permitted, provided the original author(s) and the copyright owner(s) are credited and that the original publication in this journal is cited, in accordance with accepted academic practice. No use, distribution or reproduction is permitted which does not comply with these terms. 